\title{
Ecological and Health Infrastructure Factors Affecting the Transmission and Mortality of COVID-19
}

\author{
Le $\mathrm{NK}^{1}$, Le $\mathrm{AV}^{2}$, Parikh J ${ }^{3}$, Brooks JP ${ }^{4}$, Gardellini $\mathrm{T}^{3}$ and Izurieta $\mathrm{R}^{*_{3}}$ \\ ${ }^{1}$ Morsani College of Medicine, University of South Florida, Tampa, FL, USA \\ ${ }^{2}$ Department of Biomedical Sciences, University of Central Florida, Orlando, FL, USA \\ ${ }^{3}$ Global Communicable Disease Concentration, College of Public Health, University of South Florida, Tampa, FL, USA \\ ${ }^{4}$ Department of Allergy and Immunology, Children's National Hospital, Washington, DC, USA
}

*Corresponding author: Izurieta R, Global Communicable Disease Concentration, College of Public Health, University of South Florida, Tampa, FL, USA, Tel: +1-8133944281, E-mail: ricardoi@usf.edu

Citation: Le NK, Le AV, Parikh J, Brooks JP, Gardellini T, et al. (2021) Ecological and Health Infrastructure Factors Affecting the Transmission and Mortality of COVID-19. J Adv Virol Res 1(1): 101. doi: 10.15744/javr.2021.1.101

Received Date: December 22, 2020 Accepted Date: January 11, 2021 Published Date: January 13, 2021

\begin{abstract}
Background: The coronavirus disease 2019 (COVID-19) has be designated a pandemic less than 4 months after its first outbreak. Due to the novelty of the virus, there is little understanding of how ecological factors affect transmission of the coronavirus. This study aims to determine the relationship of temperature, absolute humidity, and health infrastructure on COVID-19 transmission and mortality.

Methods: Epidemiological data was obtained for all US states and countries worldwide between January 22 and March $23,2020$. Univariate and multivariate linear regressions were done comparing temperature, absolute humidity, and health infrastructure with cases and deaths.

Results: The regression models revealed that temperature and humidity significantly affect the number of confirmed cases ( $\mathrm{p}=0.0123$ and $\mathrm{p}=0.0072$, respectively).

Conclusions: The transmission of COVID-19 seems to thrive in colder and drier environments. Despite this relationship, more efforts are needed to ensure compliance to "social distancing" and other public health measures rather than relying on temperature alone to reduce COVID-19 cases.

Keywords: COVID-19; Temperature; Humidity; Health Infrastructure; Transmission

List of abbreviations: COVID-19: Coronavirus Disease; US: United States; SARS-CoV-2: Severe Acute Respiratory Syndrome Coronavirus 2; CFCIA: Central Intelligence Agency; ICU: Intensive Care Unit; SARS: Severe Acute Respiratory Syndrome
\end{abstract}

\section{Background}

Cases of the novel coronavirus disease 2019 (COVID-19), first identified in Wuhan, Hubei, China early in December 2019, have spread globally and have been designated as a pandemic by the World Health Organization in a brief span of approximately four months [1,2]. COVID-19, caused by the severe acute respiratory syndrome coronavirus 2 (SARS-CoV-2), has had on-going transmission despite quarantine, increased hand hygiene, social distancing, and other public health measures [3]. The outbreaks outside of China, including Western Europe, the United States (US), and Iran have grown exponentially [4].

As the virus is characterized, strategies to combat COVID-19 are continually being developed. It has been suggested that SARS$\mathrm{CoV}-2$ may be sensitive to environmental fluctuations similar to other closely related coronaviruses (Severe acute respiratory syndrome-related coronavirus), influenza virus, and even Ebola virus [5-10]. The seasonality of influenza-like respiratory infections has already been described with annual epidemics associated with cold-dry and humid-rainy climates in temperate and tropical regions respectively [6]. The intensity of seasonal humidity has been reported as the variable that best explains the annual epidemics of influenza-like respiratory infections [6]. The implications of temperature, humidity, and health infrastructure dependence have the potential to assist in the efforts to curb the spread of COVID-19, especially as the summer approaches. This study attempts to elucidate the effects of meteorological conditions and health infrastructure on the transmission of COVID-19.

\section{Methods}

Epidemiological data, for all countries affected, tracking COVID-19 cases and deaths from Johns Hopkins Center for Systems 
Science and System were collected between January 22, 2020 and March 23, 2020 [11]. US-specific cases, deaths, and number of tests data were collected from the COVID Tracking Project [12]. The country population data was based on the CIA World Factbook's 2020 estimates, and the US population was based on the US Census Bureau's 2019 estimates [13,14].

The number of US hospital beds in 2018 was found on the Kaiser Family Foundation webpage, while the number of hospital beds by country was found on the World Bank webpage [15,16]. ICU and critical care bed data for the US and other countries were collected from the Modern Healthcare site and previously published data, respectively [17-19]. The number of ports by country and state was provided by the World Port Source [20]. The number of primary international airports for the US, as defined as having over 10,000 passenger boardings per year, was based on the Federal Aviation Administration classification [21]. Data on ports of entry was collected from the US Customs and Border Protection webpage [22]. Port of entry is defined as a location where a person can lawfully enter the country.

Average temperature and relative humidity for the month of March 2020 were gathered from https:/www.timeanddate.com/ weather/ [23]. The capital city for each country and state was selected for this analysis, with the rationale being that the capital cities commonly contain the largest populations. Since absolute humidity, the amount of water in the air, has been found to be correlated with transmission of other viral diseases, the relative humidity data collected was converted to absolute humidity using the Clausius Clapeyron equation [24-27].

\section{Data analysis}

Descriptive analyses were done for cases and deaths. The maps were created using ArcMap 10.7.1, a part of the ESRI ArcGIS suite. Separate multivariate linear regressions were utilized to determine the association between cases with temperature and humidity and deaths with health infrastructure for the states and countries. Stepwise regressions with backward elimination were used to fit the regression models. When studying the US, the covariates for modeling cases were population size and number of tests done, international airports, ports, and ports of entry, while the covariates for modeling deaths were the same as the cases with the addition of number of hospital beds and ICU beds. When analyzing the countries, the covariates for modeling cases were population size, number of tests done, and number of ports. The covariates when modeling for deaths added the number of hospitals, ICU, and critical care beds. Significance was defined as p D 0.05. Data was analyzed using SAS 94, accessed from the University of South Florida.

\section{Results}

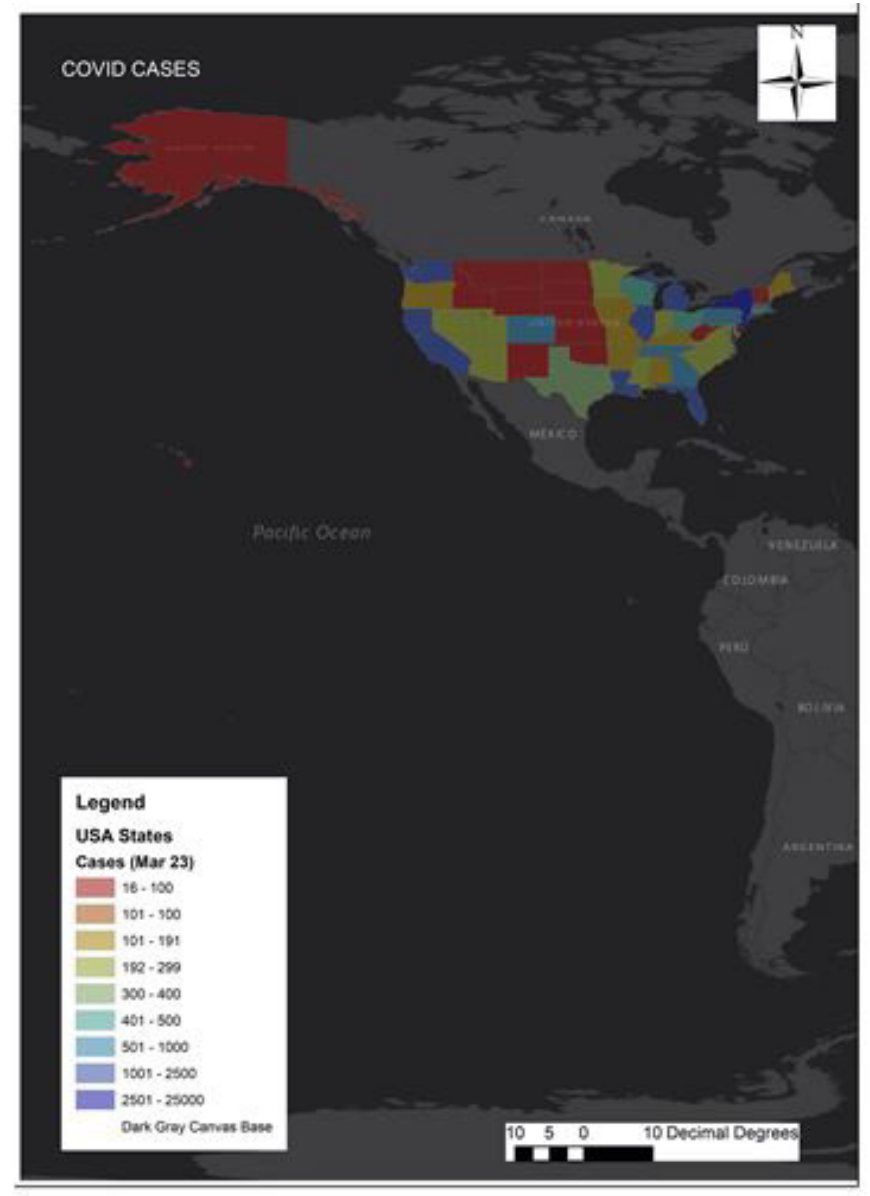

Figure 1: US map indicating confirmed cases 
There have been 42,087 confirmed cases (Figure 1) and 468 deaths (Figure 2) within the 50 US states. Among 168 affected countries, there have been 378,547 confirmed cases (Figure 3) and 16,505 deaths (Figure 4). Univariate and multivariate linear regressions comparing temperature vs. cases, temperature vs. deaths, absolute humidity vs. cases, absolute humidity vs. deaths, and critical care/ICU beds vs. deaths were done for US states and countries. The temperature and absolute humidity regressions for the US weren't significant, but the adjusted ICU beds vs. deaths regression was significant (parameter estimate $=0.01798$ and $\mathrm{p}=0.0162$ ).

When comparing the countries worldwide, the unadjusted linear regression comparing temperature vs. cases and humidity vs. cases were significant. The country univariate model for temperature vs. cases had a parameter estimate of -107.44734 and a $\mathrm{p}$-value $=$ 0.0123. Parameter estimate for the country univariate model humidity vs cases was -23.73851 with a p-value of 0.0072 . Additionally, the univariate model for critical care beds vs. deaths was significant (parameter estimate $=0.04828$ and $\mathrm{p}=0.0036$ ).

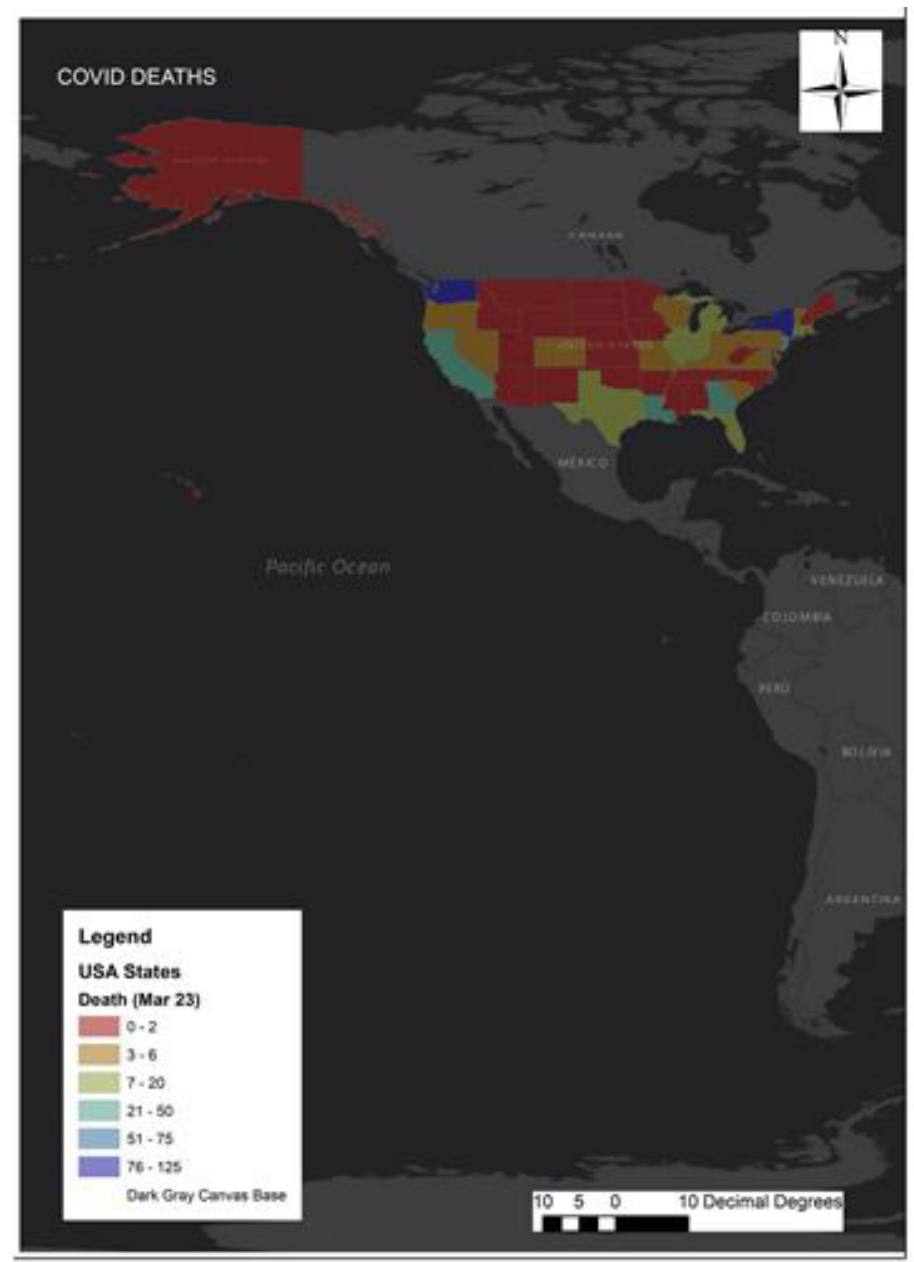

Figure 2: US map indicating deaths

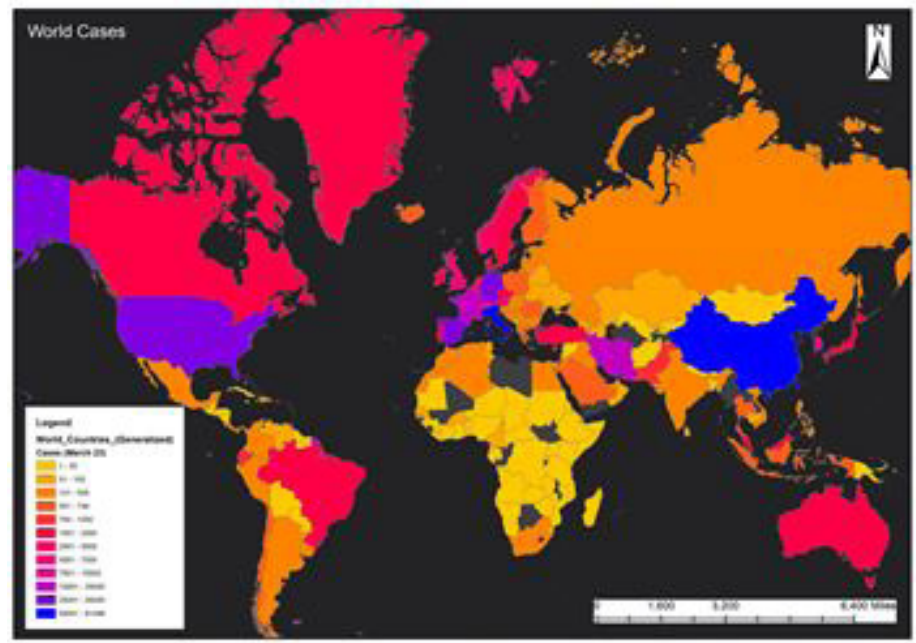

Figure 3: World map indicating confirmed cases 


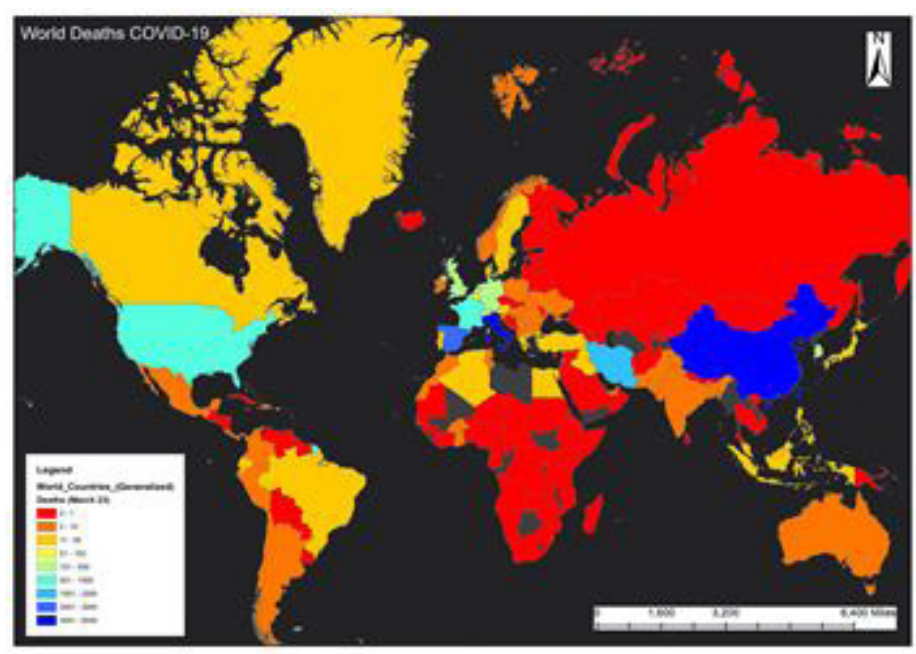

Figure 4: World map indicating deaths

\section{Discussion}

COVID-19 is a highly infectious, novel disease that has swiftly infected populations globally. Based on our study, there appears to be a negative relationship between temperature/absolute humidity and the number of cases. The higher the temperature and absolute humidity, the lower the case numbers.

Furthermore, health infrastructure, such as critical care and ICU beds, was significantly correlated with mortality. We found an unexpected relationship between increased deaths and increased critical care/ICU beds. This could be explained by testing and treatment disparities between countries. High-income countries are more likely to have a greater quantity of ICU/critical care beds and, therefore, have the ability to test and care for more severe patients [16]. As the patients cared for in the ICU are critically ill, we would expect a higher mortality rate. Similarly, many of the ICU's in high-income countries are overcapacity, which could further result in increased reported mortality rates [28]. As we begin to provide more tests and learn how to better manage patients with COVID-19, this relationship is expected to invert.

Given our more robust data from the start of the outbreak to late March 2020, it's likely that the SARS-CoV-2 transmits more readily in colder and dry climates. The implications of this effect still need to be studied. Though temperature and humidity may be a factor in COVID-19 transmission, it is not as major of a determinant such as human behavior and hygiene. Despite the significance being found when comparing countries, the relationship was not as apparent when looking specifically at the US. One factor to consider is that there may still be a lag time in testing, especially in low-and-middle- income countries. Many of the countries within the African continent are only recently starting to have confirmed cases. Therefore, the true effect of temperature and humidity on COVID-19 will only be revealed over time.

Prior studies have used preliminary, regional data that shows a slight association between temperature and humidity and cases of COVID-19. Similar to influenza, COVID-19 seems to spread more readily in colder and drier climates [29-31]. This effect has been seen on the coronavirus' survivability on surfaces as well [32,33]. It is hypothesized that temperature and humidity not only affect viral transmissibility through respiratory droplets, but that the lower temperatures alone can result in systematically worse immune systems [34,35].

There has also been contradictory evidence that the effect of temperature and humidity is minimal to none. The 2003 Severe Acute Respiratory Syndrome (SARS) outbreak dissipation has been credited due to warmer weather [5]. However, the success in reducing SARS cases was really attributable to increased intensive precautions and public health measures [36]. Regardless of the effects of meteorological conditions, it's unlikely that there will be a significant decrease in COVID-19 cases this coming summer due to temperature or humidity changes alone. As the coronavirus is a novel disease, there is no predictability as to how it will behave, particularly when the entire world population lacks any immunity. At this point, the best response to thwart the virus is to ensure continual isolation, prompt identification of cases and contacts, use of masks, strict quarantines, travel restrictions, "social distancing," hand and general hygiene, and other intensive efforts rather than relying on a change in season [37,38].

After monitoring the COVID-19 outbreak in Western Europe, further consideration must be given to the preparedness of the US healthcare system. The continued growth of cases is in large part due to the overload of the healthcare infrastructure [39]. The US is already experiencing strain on its limited critical care facilities with mechanical ventilators and a shortage of personal protective equipment (PPE) [40,41]. Healthcare professionals without easy access to PPE have resorted to either reusing/substituting masks or being left unprotected [42]. Given that the US is facing the COVID-19 challenge at a later stage of the pandemic, the global reserves of PPE have largely been depleted [43]. This PPE shortage is further exacerbated by public hysteria and hoarding of masks [44]. If precautionary measures do not improve, the risk to frontline providers will increase and healthcare capacity will dwindle. 
In a time of high connectivity and globalization, the spread of COVID-19 is unprecedented. COVID-19 is more infectious than SARS, with a basic reproduction number $\left(\mathrm{R}_{0}\right)$ between 2.2 and 6.7 [45-48]. Even though quarantines and curfews have been instituted, many are unenforceable and allow for the flexibility for both domestic and international travel [49]. Understandably, a true shut down would be too difficult given the monumental financial and social consequences. Supply chain disruptions have already resulted in loss of revenue and supply shortages for businesses and cities as well as major disruptions to the global economy [50].

A limitation of this study is that the temperature and humidity can vary greatly across a state or country. For ease of analysis, this study generalized the capital city's temperature and humidity for the entire state and country. Therefore, the true effect of temperature and humidity on COVID-19 may be different. Additionally, it's difficult to account for the variations in human behaviors and country restrictions in response to this outbreak as people may or may not be participating in the recommended public health guidelines. Lastly, we were unable to obtain data on testing practices and the number of ICU/critical care beds from all affected countries.

As we are still in the early stages of the pandemic, it's hard to predict how the coronavirus will resolve. The hope is that with summer soon approaching, the global community beginning to enforce more stringent public health precautions, and the use of promising pharmacological interventions, we will begin to curb the transmission of COVID-19.

\section{Conclusions}

The transmission of COVID-19 seems to thrive in colder and drier environments. Therefore, seasonal epidemic outbreaks as well as a heterogeneous geographic distribution of the disease are expected. During the first epidemic wave, it is expected a clear seasonal pattern of transmission since herd immunity has not been established; nevertheless, after natural or artificial immune protection is developed by the population, it is expected annual epidemics associated with cold-dry and humid-rainy climates in temperate and tropical regions respectively. Despite this relationship, more efforts are needed to ensure compliance to use of masks, "social distancing" and other public health measures rather than relying on temperature alone to reduce COVID-19 cases.

\section{Declarations}

\section{Ethics approval and consent to participate}

Not applicable. All data used in this study was public data.

\section{Consent for publication}

Not applicable

\section{Availability of data and materials}

The datasets used and/or analyzed during the current study are available from the corresponding author on reasonable request

\section{Competing interests}

The authors declare that they have no competing interests.

\section{Funding}

None

\section{Authors' contributions}

NKL created, analyzed, and interpreted the dataset in addition to preparing the manuscript. AVL created the dataset and helped prepare the manuscript. JP analyzed and interpreted data and contributed to the manuscript. JPB contributed to the manuscript. TG contributed to the manuscript. RI analyzed and interpreted data and contributed to the manuscript. All authors read and approved the final manuscript.

\section{References}

1. Huang C, Wang Y, Li X, Ren L, Zhao J, et al. (2020) Clinical features of patients infected with 2019 novel coronavirus in Wuhan, China. Lancet 395 : $497-506$.

2. World Health Organization (2020) WHO Director-General's opening remarks at the media briefing on COVID-19, Switzerland.

3. Gorbalenya AE, Baker SC, Baric RS, de Groot RJ, Drosten C, et al. (2020) Severe acute respiratory syndrome-related coronavirus: The species and its viruses - a statement of the Coronavirus Study Group. Nature Microbiology 10.1038/s41564-020-0695-z.

4. Kucharski AJ, Russell TW, Diamond C, Liu Y, Edmunds J , et al. (2020) Early dynamics of transmission and control of COVID-19: a mathematical modelling study. Lancet Infect Dis 20: 553-8.

5. Yip C, Chang WL, Yeung KH, Yu IT (2007) Possible meteorological influence on the severe acute respiratory syndrome (SARS) community outbreak at Amoy Gardens, Hong Kong. J Environ Health 70: 39-46. 
6. Thai PQ, Choisy M, Duong TN, Thiem VD, Yen NT, et al. (2015) Seasonality of absolute humidity explains seasonality of influenza-like illness in Vietnam. Epidemics 13: 65-73.

7. Ng S, Cowling BJ (2014) Association between temperature, humidity and ebolavirus disease outbreaks in Africa, 1976 to 2014. Euro Surveill 19: 10.2807/15607917.es2014.19.35.20892.

8. Lowen AC, Steel J (2014) Roles of humidity and temperature in shaping influenza seasonality. J Virol 88: 7692-5.

9. Chu CM, Tian SF, Ren GF, Zhang YM, Zhang LX, et al. (1982) Occurrence of temperature- sensitive influenza A viruses in nature. J Virol 41: 353-9.

10. Bhatt S, Gething PW, Brady OJ, Messina JP, Farlow AW, et al. (2013) The global distribution and burden of dengue. Nature 496: 504-7.

11. Johns Hopkins University (2020) Coronavirus COVID-19 Global Cases by the Center for Systems Science and Engineering (CSSE) at Johns Hopkins University (JHU) 2020, USA.

12. The COVID Tracking Project (2020) COVID Tracking Project, USA.

13. Central Intelligence Agency (2020) The World Factbook, USA.

14. US Census Bureau (2019) State Population Totals and Components of Change: 2010-2019, USA.

15. Kaiser Family Foundation (2018) Hospital Beds per 1,000 Population by Ownership Type 2018, USA.

16. The World Bank (2020) Hospital beds (per 1,000 people), USA.

17. Broderick T (2020) COVID-19 could fill hospital beds, but how many are there? Modern Healthcare, USA.

18. Rhodes A, Ferdinande P, Flaatten H, Guidet B, Metnitz PG, et al. (2012) The variability of critical care bed numbers in Europe. Intensive Care Med 38: 1647-53.

19. Phua J, Faruq MO, Kulkarni AP, Redjeki IS, Detleuxay K, et al. (2020) Critical Care Bed Capacity in Asian Countries and Regions. Crit Care Med 48: 654-62.

20. World Port Source (2020) World Ports by Country, USA.

21. Wikiwand (2020) List of airports in the United States: Wikipedia, USA.

22. Customs and Border Protection (2019) Locate a Port of Entry: U.S. Customs and Border Protection; 2019, USA.

23. TimeandDate (2020) World Temperatures - Weather Around The World, USA.

24. Barreca AI, Shimshack JP (2012) Absolute humidity, temperature, and influenza mortality: 30 years of county-level evidence from the United States. Am J Epidemiol 176: S114-22.

25. Shaman J, Goldstein E, Lipsitch M (2011) Absolute humidity and pandemic versus epidemic influenza. Am J Epidemiol 173: 127-35.

26. Bolton D (1980) The Computation of Equivalent Potential Temperature. Monthly Weather Review 108: 1046-53.

27. Iribarne JV, Godson WL (1981) Atmospheric thermodynamics (2nd Edn) Dordrecht, Holland, Boston, USA.

28. Horowitz J (2020) Italy’s Health Care System Groans Under Coronavirus - a Warning to the World, USA.

29. Wang M, Jiang A, Gong L, Lu L, Guo W, et al. (2020) Temperature Significantly Change COVID-19 Transmission in 429 Cities. MedRxiv 10.1101/2020.02.22.20025791.

30. Luo W, Majumder MS, Liu D, Poirier C, Mandl KD, et al. (2020) The role of absolute humidity on transmission rates of the COVID-19 outbreak. MedRxiv 10.1101/2020.02.12.20022467.

31. Bu J, Peng D-D, Xiao H, Yue Q, Han Y, et al. (2020) Analysis of meteorological conditions and prediction of epidemic trend of 2019-nCoV infection in 2020. MedRxiv 10.1101/2020.02.13.20022715.

32. Casanova LM, Jeon S, Rutala WA, Weber DJ, Sobsey MD (2010) Effects of air temperature and relative humidity on coronavirus survival on surfaces. Appl Environ Microbiol 76: 2712-7.

33. van Doremalen N, Bushmaker T, Morris DH, Holbrook MG, Gamble A, et al. (2020) Aerosol and Surface Stability of SARS-CoV-2 as Compared with SARSCoV-1. N Engl J Med 382: 1564-7.

34. Moriyama M, Ichinohe T (2019) High ambient temperature dampens adaptive immune responses to influenza A virus infection. Proc Natl Acad Sci U S A 116: 3118-25.

35. Kudo E, Song E, Yockey LJ, Rakib T, Wong PW, et al. (2019) Low ambient humidity impairs barrier function and innate resistance against influenza infection. Proc Natl Acad Sci U S A 116: 10905-10.

36. Knobler S (2004) Institute of Medicine (U.S.). Forum on Microbial Threats., Institute of Medicine (U.S.). Board on Global Health. Learning from SARS : preparing for the next disease outbreak: workshop summary. Washington, DC: National Academies Press, USA.

37. Wu JT, Leung K, Leung GM (2020) Nowcasting and forecasting the potential domestic and international spread of the 2019-nCoV outbreak originating in Wuhan, China: a modelling study. Lancet 395: 689-97.

38. Wilder-Smith A, Freedman DO (2020) Isolation, quarantine, social distancing and community containment: pivotal role for old-style public health measures in the novel coronavirus (2019-nCoV) outbreak. J Travel Med 27: 10.1093/jtm/taaa020.

39. Verelst F, Kuylena E, Beutels P (2020) Indications for healthcare surge capacity in European countries facing an exponential increase in COVID19 cases. Euro Surveill 25: 10.2807/1560-7917.ES.2020.25.13.2000323.

40. Rubinson L, Vaughn F, Nelson S, Giordano S, Kallstrom T, et al. (2010) Mechanical ventilators in US acute care hospitals. Disaster Med Public Health Prep 4: 199-206.

41. Halpern NA, Tan KS, Taskforce SV (2020) U.S. ICU Resource Availability for COVID-19 2020, USA.

42. Centers for Disease Control and Prevention (2019) Crisis/Alternate Strategies, USA.

43. Schnirring L (2020) As Italy COVID-19 cases soar, WHO tackles PPE, test shortages: Center for Infectious Disease Research and Policy; 2020 , USA.

44. Wang CJ, Ng CY, Brook RH. Response to COVID-19 in Taiwan: Big Data Analytics, New Technology, and Proactive Testing. JAMA 323: 1341-2.

45. Liu JH, Xiao J, He G, Kang M, Rong Z, et al. (2020) Time-varying transmission dynamics of Novel Coronavirus Pneumonia in China. BioRxiv 10.1101/2020.01.25.919787.

46. Shen M, Peng Z, Xiao Y, Zhang L (2020) Modelling the epidemic trend of the 2019 novel coronavirus outbreak in China. The Innovation 10.1016/j. xinn.2020.100048. 
47. Li Q, Guan X, Wu P, Wang X, Zhou L, et al. (2020) Early Transmission Dynamics in Wuhan, China, of Novel Coronavirus-Infected Pneumonia. N Engl J Med 382: 1199-207.

48. Read JM, Bridgen JR, Cummings DA, Ho A, Jewell CP (2020) Novel coronavirus 2019-nCoV: early estimation of epidemiological parameters and epidemic predictions. MedRxiv 10.1101/2020.01.23.20018549.

49. Wu Z, McGoogan JM (2020) Characteristics of and Important Lessons From the Coronavirus Disease 2019 (COVID-19) Outbreak in China: Summary of a Report of 72314 Cases From the Chinese Center for Disease Control and Prevention. JAMA 323: 1239-42.

50. McKibbin WJ, Fernando R (2020) The Global Macroeconomic Impacts of COVID-19: Seven Scenarios. CAMA Working Paper No 19/2020: 10.2139/ ssrn.3547729. 